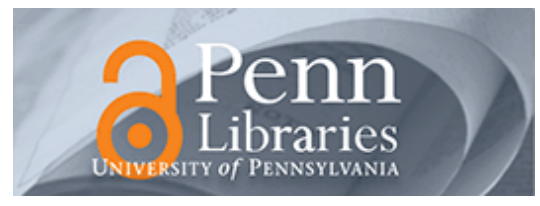

University of Pennsylvania

ScholarlyCommons

Accounting Papers

Wharton Faculty Research

$6-2002$

\title{
Estimating the Value of Employee Stock Option Portfolios and Their Sensitivities to Price and Volatility
}

John E. Core

University of Pennsylvania

Wayne R. Guay

University of Pennsylvania

Follow this and additional works at: https://repository.upenn.edu/accounting_papers

Part of the Accounting Commons

\section{Recommended Citation}

Core, J. E., \& Guay, W. R. (2002). Estimating the Value of Employee Stock Option Portfolios and Their Sensitivities to Price and Volatility. Journal of Accounting Research, 40 (3), 613-630. http://dx.doi.org/ 10.1111/1475-679X.00064

This paper is posted at ScholarlyCommons. https://repository.upenn.edu/accounting_papers/30

For more information, please contact repository@pobox.upenn.edu. 


\title{
Estimating the Value of Employee Stock Option Portfolios and Their Sensitivities to Price and Volatility
}

\author{
Abstract \\ The costs associated with compiling data on employee stock option portfolios is a substantial obstacle in \\ investigating the impact of stock options on managerial incentives, accounting choice, financing \\ decisions, and the valuation of equity. We present an accurate method of estimating option portfolio \\ value and the sensitivities of option portfolio value to stock price and stock-return volatility that is easily \\ implemented using data from only the current year's proxy statement or annual report. This method can \\ be applied to either executive stock option portfolios or to firm-wide option plans. In broad samples of \\ actual and simulated CEO option portfolios, we show that these proxies capture more than $99 \%$ of the \\ variation in option portfolio value and sensitivities. Sensitivity analysis indicates that the degree of bias in \\ these proxies varies with option portfolio characteristics, and is most severe in samples of CEOs with a \\ large proportion of out-of-the-money options. However, the proxies' explanatory power remains above \\ $95 \%$ in all subsamples.

\section{Disciplines} \\ Accounting
}




\title{
ESTIMATING THE VALUE OF EMPLOYEE STOCK OPTION PORTFOLIOS AND THEIR SENSITIVITIES TO PRICE AND VOLATIITY
}

\author{
John Core \\ The Wharton School \\ University of Pennsylvania \\ 2400 Steinberg-Dietrich Hall \\ Philadelphia, PA 19104-6365 \\ email: jcore@wharton.upenn.edu \\ phone: (215) 898-4821 \\ fax: (215) 573-2054 \\ Wayne Guay \\ The Wharton School \\ University of Pennsylvania \\ 2400 Steinberg-Dietrich Hall \\ Philadelphia, PA 19104-6365 \\ email: guay@wharton.upenn.edu \\ phone: (215) 898-7775 \\ fax: (215) $573-2054$
}

Current Draft: January, 2002

We appreciate helpful comments from Joy Begley, Jarrad Harford, Bob Holthausen, S.P. Kothari, Rick Lambert, Christian Leuz, Cathy Schrand, Abbie Smith (the editor), two anonymous referees, and seminar participants at the 1999 Managerial Accounting Conference and the 1999 American Accounting Association Conference. 


\title{
ESTIMATING THE VALUE OF EMPLOYEE STOCK OPTION PORTFOLIOS AND THEIR SENSITIVITIES TO PRICE AND VOLATILITY
}

\begin{abstract}
The costs associated with compiling data on employee stock option portfolios is a substantial obstacle in investigating the impact of stock options on managerial incentives, accounting choice, financing decisions, and the valuation of equity. We present an accurate method of estimating option portfolio value and the sensitivities of option portfolio value to stock price and stock-return volatility that is easily implemented using data from only the current year's proxy statement or annual report. This method can be applied to either executive stock option portfolios or to firm-wide option plans. In broad samples of actual and simulated CEO option portfolios, we show that these proxies capture more than $99 \%$ of the variation in option portfolio value and sensitivities. Sensitivity analysis indicates that the degree of bias in these proxies varies with option portfolio characteristics, and is most severe in samples of CEOs with a large proportion of out-of-the-money options. However, the proxies' explanatory power remains above $95 \%$ in all subsamples.
\end{abstract}




\section{Introduction}

A large body of research examines the role of stock options in executive compensation and incentives. In addition, because company-wide option plans have become a substantial component of many firms' equity capital, a growing body of research on options addresses the valuation, corporate finance, and incentive implications of firm-level option plans (e.g., Aboody [1996]; Core and Guay [2001a]). To study these issues, researchers need accurate and easily-computed proxies for option portfolio value and the sensitivity of option portfolio value to changes in stock price and to changes in stock-return volatility (Abowd and Kaplan [1999]). A few prior researchers estimate the value and sensitivities of option portfolios by gathering details on each of the annual option grants that comprise the portfolio (e.g., Jensen and Murphy [1990]). To estimate a "full information" measure for a single executive's option portfolio, the researcher must examine as many as ten years of proxy statements for a company that grants options with ten-year maturities. These data collection costs motivate most researchers to use readily available measures (e.g., the number of options held or the characteristics of the most recent option grant) as proxies for the value and sensitivities of option portfolios.

We provide and validate an easy-to-implement alternative method to compute proxies for option portfolio value and sensitivities to stock price and volatility. To estimate the value or sensitivity of an executive's option portfolio, we require data from a single corporate proxy statement. We refer to this technique as the "one-year approximation" (OA) method. The OA method can also be applied to firm-wide option plans to estimate value or sensitivities using data in a single corporate annual report.

The OA method uses the precise characteristics of newly granted options and the average characteristics of previously granted unexercisable and exercisable options to value an option portfolio as the combination of three separate grants. We also use this method to compute the sensitivities of 
portfolio value to stock price and stock-return volatility. Using Guay's [1999] hand-collected sample of CEO option portfolios and a sample of simulated option portfolios, we document that for the typical option portfolio, the OA proxies exhibit little bias and are highly correlated with the measures one would obtain with full information about the option portfolios (explained variation exceeds $99 \%$ in most cases).

Although the OA proxies are on average unbiased in a broad sample of firms, we document predictable biases in subsamples where the stock price is low relative to the average exercise price of the options in the portfolio. For example, in subsamples where a large fraction of options are out-of-themoney, the percentage error in estimates of portfolio value and sensitivity to stock price can exceed $20 \%$. However, the cross-sectional variation explained by the OA proxies remains above $96 \%$ in all subsamples we examine. These biases are important to researchers examining samples of CEOs with a large proportion of underwater options. We expand on these points further in Section 3.3, and discuss an approach to extending our method to incorporate information from past stock returns and past proxy statements.

We also show that compared to OA proxies, measurement error in proxies used by prior studies is more highly correlated with option portfolio characteristics (e.g., stock-return volatility, price, dividend yield, and the average price-to-strike ratio of the options in the portfolio). Because these parameters are likely to be correlated with firm characteristics such as past performance, size, leverage and growth, tests that use the OA proxies are less susceptible to inference problems.

In the next section, we describe the OA method for computing option portfolio value and sensitivities to stock price and volatility. In Section 3, we describe our data and compare the OA proxies to option portfolio value and sensitivities computed using full information about executives' 
option portfolios. We also examine the robustness of OA proxies in subsamples of the data. We conclude with Section 4.

\section{A One-Year Approximation Method for Estimating Option Portfolio Value and Sensitivities to Stock Price and Stock-Return Volatility}

Consistent with most prior research, we value employee stock options using the Black-Scholes [1973] model, as modified by Merton [1973] to account for dividend payouts. ${ }^{1}$ We define the "option portfolio value" as the aggregate value of the options held in the portfolio. The "sensitivity to stock price" is the change in option portfolio value for a $1 \%$ change in the stock price, and the "sensitivity to stockretum volatility" is the change in option portfolio value for a 0.01 change in the annualized standard deviation of stock returns. Appendix A describes the option valuation model and sensitivities in greater detail.

Figure 1 illustrates the importance of incorporating variation in option characteristics into estimates of the sensitivity to stock price and the sensitivity to stock-return volatility. For a typical executive stock option, we plot the two sensitivities for price-to-strike ratios ranging from 0.5 to 2.0 . The price-to-strike ratio is the stock price divided by the exercise price and measures the extent to which the option is "in the money." The plots demonstrate that both sensitivities vary considerably with the price-to-strike ratio. Options that are deep in the money are very sensitive to changes in stock price and very insensitive to changes in stock-return volatility. In contrast, as options move out of the money, the sensitivity to stock price drops steadily while the sensitivity to volatility rises and peaks at a price-to-

\footnotetext{
${ }^{1}$ Employee stock options are likely to be exercised earlier than their maturity date (e.g., Huddart [1994], Cuny and Jorion [1995]). In addition, employees lower in the organization tend to exercise options earlier than executive-level employees (Huddart and Lang [1996]). While we do not have a direct estimate of expected time-to-maturity, all of our results are robust to reducing the remaining time-to-maturity of all options by a constant percentage, such as $40 \%$ or $60 \%$. For arguments that Black-Scholes is inappropriate for pricing employee options, see Lambert, Larcker, and Verrecchia [1991]; for a counterargument, see Core and Guay [2001b].
} 
strike ratio of about 0.6 for the option parameters chosen here. Thus, proxies that fail to capture variation in options' characteristics are likely to measure portfolio sensitivities with considerable error.

If the details of each grant in the option portfolio are known, the above sensitivities can be easily estimated as the partial derivatives of the option portfolio's value with respect to stock price and stockreturn volatility. All of the necessary information for new option grants is disclosed in the firm's annual proxy statement for a firm's five highest paid executives. ${ }^{2}$ Unfortunately for the researcher, the proxy statement does not disclose complete data on previously granted options. Thus, extensive data collection from past proxy statements is required. The researcher must carefully determine which of the previously granted options have been exercised by the optionholders, and which options remain in the portfolio. Recent studies by Hall and Liebman [1998], Mehran, Nogler, and Schwartz [1998], and Guay [1999] use extensive hand-collected data to construct a sample of CEOs' option portfolios for the purpose of estimating "full information" (FI) sensitivities to stock price and stock-return volatility. Using these methods to construct a single CEO's option portfolio requires as many as ten years of proxy statements for a firm that grants options with ten-year maturities.

In contrast to the FI method, the OA method requires information from only the most recent proxy statement and is summarized as follows: New option grant values and sensitivities are computed directly because the proxy statement discloses all the inputs necessary for the Black-Scholes model. The proxy statement discloses separate information on unexercisable and exercisable previously-granted options, and we treat these two types of options as two single grants. The exercise price of each "grant"

\footnotetext{
${ }^{2}$ In the following discussion, we discuss the OA method in the context of executive option portfolio valuation. We describe its application to firm-wide option plans at the end of this Section.
} 
is derived from the average realizable value of the options, and we assume that unexercisable options have a time-to-maturity that is three years greater than that of the exercisable options.

The OA method requires a current-year proxy statement and estimates of the six inputs into the Black-Scholes model. Three of the inputs (stock price, expected stock-return volatility, and expected dividend yield) are readily available. The firm's stock price is a common input for all outstanding employee stock options. Further, as a first approximation, the expected stock-return volatility and expected dividend yield over an option's life are likely to be roughly the same across an executive's options, and can be estimated using Compustat and CRSP data.

For new grants, two of the remaining three inputs (exercise price and time-to-maturity) are easily identified from data disclosed in the proxy statement. The final input, an estimate of the risk-free rate corresponding to the time-to-maturity of new options, is readily available from an electronic source such as CRSP. This information is sufficient to compute the value and sensitivities of the new option grant using Black-Scholes.

For previously granted options, we must estimate the exercise prices and times-to-maturity. To estimate the exercise prices, we use the realizable values (excess of stock price over exercise price) disclosed in the proxy statement for each top-five executive's unexercisable and exercisable options. Because the value and sensitivities of newly granted options are computed separately as described above, the number and fiscal year-end realizable value of new options must be deducted from the number and realizable value of unexercisable options. ${ }^{3}$ Dividing the unexercisable (excluding new grants) and exercisable realizable values by the number of unexercisable and exercisable options held by the

\footnotetext{
${ }^{3}$ In those few cases when the number of new options granted exceeds the number of unexercisable options (due to immediate vesting of some or all new options), the excess realizable value and excess number of options is deducted
} 
executive, respectively, yields estimates of, on average, how far each of these groups of options are "in the money." Subtracting these average "profits" per option from the firm's stock price generates estimates of the average exercise price of the executives' unexercisable and exercisable options.

We note that the estimated average exercise prices will understate the true average exercise prices when the portfolio contains out-of-the-money options. The proxy statement does not report the number of options that are out-of-the-money, and therefore it is not possible to determine the extent to which the exercise price exceeds the stock price for the out-of-the-money options. As a result, we assume out-of-the-money options have exercise prices equal to the stock price. We examine the sensitivity of the OA method to this measurement issue in Section 3.3.

To capture variation in the remaining time-to-maturity of previously granted options, we again discriminate between executives' unexercisable and exercisable options. Because nearly all firms set a vesting period on option grants, options that are exercisable are expected to have fewer years remaining to maturity than options that are unexercisable. If a firm grants options in the most recent fiscal year, we set the time-to-maturity of previously granted unexercisable options equal to the time-to-maturity of the recent option grant minus one year. Previously granted exercisable options for these firms are designated a remaining time-to-maturity of three years less than that of the unexercisable options. ${ }^{5}$ If no

from the respective realizable value and number of exercisable options.

${ }^{4}$ This method extends and validates the method described in Murphy [1999], which computes the sensitivity of the total option portfolio value to stock price using the mean price-to-strike ratio and assuming a five-year maturity for all options.

${ }^{5}$ We assume the remaining to time-to-maturity for unexercisable options is one year less than the maturity of the new grant, based on the assumption that option vesting periods are about 2 years, on average (Kole [1997]). Evidence in Kole [1997] suggests that while vesting practices for option plans do differ across firms, the variation remains within fairly tight bounds (e.g., the average vesting restriction varies from approximately 20 to 28 months across subsamples). Our assumption that exercisable options have an average maturity of only three years less than the maturity of unexercisable options is based on our expectation that some older grants have been exercised early (Hemmer, Matsunaga, and Shevlin [1996]). Our results are robust to alternative assumptions that exercisable options 
grant is made in the most recent fiscal year, we set the times-to-maturity of unexercisable and exercisable options to nine and six years, respectively, since most firms grant new options with ten years to maturity. Finally, we estimate risk-free interest rates to correspond to each option's assumed time-tomaturity using Treasury yields at the end of the fiscal year in which the portfolio sensitivities are computed. The estimated value and sensitivities of an option portfolio are equal to the sums of the value and sensitivities of newly granted options, unexercisable options, and exercisable options.

The OA method is easily modified to estimate the value and sensitivities of firm-wide option plans using data from the current year's annual report. Beginning in December, 1996, required annual report disclosures include the total number of options outstanding at the end of the fiscal year, the number and weighted average exercise price of options granted in the current year, the total number of options exercisable, the weighted average exercise prices of both total options outstanding and exercisable options, and the weighted average remaining times-to-maturity for both total options outstanding and exercisable options. This data is sufficient to use the OA method to compute option plan value and sensitivities to stock price and volatility.

\section{Testing the Validity and Robustness of the One-Year Approximation Method}

\subsection{THE DATA}

To assess how well the OA proxies perform, we use two samples of option portfolios with sufficient data to compute both FI sensitivities and OA sensitivities. The first sample contains the option portfolios of 228 CEOs hand collected by Guay [1999] for the December, 1993 fiscal year. The sample consists of 228 CEOs selected uniformly from the 1,000 largest firms on COMPUSTAT

have average remaining maturities of two or four years less than that of unexercisable options. Because the expected times-to-exercise are likely to be lower than the stated remaining times-to-maturity, the researcher may wish to make 
(ranked by market value of equity) as of December 31, 1988. For each CEO's option portfolio, this dataset contains all of the inputs necessary to compute the FI value and sensitivities. The typical portfolio in this sample consists of options that are in-the-money (median portfolio price-to-strike ratio of 1.27), and have several years remaining until expiration (median portfolio time-to-maturity of 7.23).

The second sample contains 10,000 simulated option portfolios. This sample allows us to more powerfully test the robustness of the OA proxies in subsamples where potential measurement error is greatest, such as portfolios that contain a substantial number of out-of-the-money options. We generate the simulated portfolios using a bootstrap procedure based on the empirical distribution of option grants within Guay's [1999] hand-collected sample. ${ }^{6}$ A comparison with the Guay [1999] sample indicates that the bootstrap procedure successfully constructs 10,000 simulated option portfolios with characteristics similar to the hand-collected sample.

\subsection{COMPARISON OF "ONE-YEAR APPROXIMATION" PROXIES AND "FULL- INFORMATION" MEASURES}

For both the hand-collected and simulated sample, we compute FI and OA method values and sensitivities to stock price and stock-return volatility following the procedures described in Section 2 . We use the FI values and sensitivities as the benchmark to assess how well the OA proxies explain variation in option portfolio values and sensitivities.

\footnotetext{
an adjustment to the remaining time-to-maturity.

${ }^{6}$ The 228 option portfolios in Guay's sample contain between one and eleven individual option grants, and the total number of individual options grants is 1,078 . The first step in the simulation procedure randomly assigns between one and eleven option grants to each of the 10,000 option portfolios based on the empirical distribution from the hand-collected sample. The number of options in each simulated grant is then randomly drawn from the empirical distribution of all 1,078 individual option grants. Finally, we randomly assign Black-Scholes parameters to the simulated option grants using the empirical distribution of parameters from the hand-collected sample. Stock price, stock return volatility and dividend yield, are portfolio-specific and all options in a given simulated portfolio are assigned the same randomly drawn parameter value. The price-to-strike ratio and remaining time-to-maturity are grant-specific, and each simulated option grant is randomly assigned a parameter value from the 1,078 option grants in the hand-collected sample. Risk-free rates are based on the yield curve used in Guay's hand-collected data.
} 
Implementation of the $\mathrm{OA}$ method requires proxy statement information. Because proxy statement data does not exist for the simulated portfolios, we construct pro-forma proxy statements that reflect the data in the simulated portfolios as they would appear in a proxy statement. For simplicity, we assume all options have a three-year vesting period, and all options with greater than 9 years to maturity are newly granted options (i.e., they were granted in the current year). Given these assumptions, options with greater than 7 years to maturity are considered unexercisable, and options with 7 or less years to maturity are considered exercisable.

We also construct pro-forma proxy statements for the hand-collected sample. Although proxy statements do exist for the firms in this sample, the data in these statements do not reconcile perfectly with the hand-collected data from the option portfolios. This is because the hand-collection process requires assumptions about the nature of grants and option exercise policy over time (see Hall and Liebman [1998] and Guay [1999]), and as a result, compiles the executives' "true" option portfolios with error. To isolate measurement error in the $\mathrm{OA}$ method from measurement error in the data collection procedures used by Guay [1999], we construct pro-forma proxy statements that reflect the realizable values inherent in the hand-collected data. In all other respects, the pro-forma proxy statements are identical to the actual proxy statements.

Table 1 illustrates that, in a broad sample, the OA proxies provide estimates of option portfolio value and sensitivities that are unbiased and highly correlated with the FI value and sensitivities. For both the hand-collected sample (Columns 1 and 2) and the simulated sample (Columns 4 and 5), the means and medians of the OA proxies for portfolio sensitivities to stock price and volatility are within $2.9 \%$ of the FI mean and median sensitivities. The deviations in sample means and medians are slightly larger for 
option portfolio value, but are not larger than $6.0 \%$ in either sample. ${ }^{7}$ None of the deviations are statistically significant in the hand-collected sample. In the simulated sample, the number of observations is substantially greater than in the hand-collected sample and the deviations for option portfolio value are statistically significant.

Columns 3 and 6 in Table 1 report that the OA proxies are nearly perfectly positively correlated with the FI values in both the hand-collected and simulated samples. The OA proxies explain more than $99.5 \%$ of the variation in option portfolio value and sensitivity to stock price. The explanatory power of the proxy for the sensitivity to stock-return volatility is slightly weaker, but the R-squared is at least $98.7 \%$ for both samples.

Reasonably accurate proxies can be obtained with less data. In untabulated tests, we explore the loss in explanatory power when the researcher does not partition previously granted options into unexercisable and exercisable portfolios and also does not partition total options outstanding into newly granted and previously granted options. Instead, all outstanding options are valued as a single grant with an assumed remaining time-to-maturity of 7.5 years. In this case, we find that the explanatory power of the proxies for option portfolio value and sensitivity to stock price remain high, with explained variation above $98.7 \%$ in both samples. The proxy for sensitivity to stock-return volatility drops slightly with explained variation of $96.0 \%(98.1 \%)$ for the hand-collected (simulated) sample. However, in subsamples described below where measurement error is expected to be present, this limitedinformation method has more severe measurement error problems.

\subsection{SENSITIVITY ANALYSIS IN SUBSAMPLES}

\footnotetext{
${ }^{7}$ Because the value of executives' stock options decreases when dividends are paid, some researchers examine executive stock options as a partial explanation for variation in dividend payout policies (e.g., Lambert, Lanen, and Larcker [1989]). Our method can be used to estimate the sensitivity of option portfolio value to dividend yield as the partial derivative of the Black-Scholes value with respect to dividend yield. The results for sensitivity to dividend yield are similar to the results reported for sensitivity to stock price and stock-return volatility (not tabulated).
} 
In this section, we explore how measurement error in the OA method varies with samplespecific characteristics, and whether the magnitude of the error is economically large in subsamples of the data. While the results in Table 1 suggest that, on average, the OA method generates accurate proxies for the FI measures in a broad sample of CEOs, the measurement error in the proxies is not completely random. Below we discuss three sources of measurement error, one of which is a first-order effect, and the second two of which are second-order in nature.

The potential for first-order measurement error in the proxies stems from lack of proxy statement disclosure about the exercise prices of previously granted options that are out-of-the-money. Because out-of-the-money options have zero realizable value, the OA method assigns these options a price-to-strike ratio of one, which is systematically too high. When the price-to-strike ratio is overstated, the estimated value of an option and the estimated sensitivity to stock price will be overstated, the estimated sensitivity to stock-return volatility will be understated (Appendix A and Figure 1). This measurement issue is most applicable to researchers examining samples of option portfolios that contain a substantial fraction of out-of-the-money options (e.g., firms that have experienced recent poor stock price performance).

In Table 2, we explore variation in measurement error across subsamples of the simulated portfolios partitioned by the observed mean price-to-strike ratio of previously granted options. We emphasize previously granted options because the value and sensitivities of newly granted options can be precisely estimated (see Section 2 ). ${ }^{8}$ The observed price-to-strike ratio is the average price-to-strike

\footnotetext{
${ }^{8}$ In Table 2, we exclude the 289 simulated portfolios that contain only newly granted options.
} 
ratio that the researcher computes using the OA method. The observed price-to-strike ratio differs from the actual price-to-strike ratio when the portfolio contains options that are out-of-the-money.

The results in Table 2 indicate that the OA method performs worse in the simulated option portfolios with low observed price-to-strike ratios. Option portfolios with an observed price-to-strike ratio of one, the lowest possible observed price-to-strike ratio for previously granted options, exhibit the greatest deviations from the FI measures and the lowest explanatory power. For example, the percentage deviation in mean sensitivity to stock price rises from $1.2 \%$ in the subsample of portfolios with observed price-to-strike ratios between 1.2 and 1.5 , to $14.7 \%$ in the subsample of portfolios with observed price-to-strike ratios of 1.00 . The explanatory power of the OA method across these two subsamples decreases from $99.8 \%$ to $96.8 \%$.

This analysis suggests that researchers should use caution when using the OA proxies in samples of executives with large proportions of underwater options, particularly in settings where the researcher is concerned with bias in the estimates as opposed to the ability of the proxies to capture cross-sectional variation. An example where bias is likely to be important is when the researcher wishes to estimate an executive's total equity incentives by adding the estimated incentives provided by options to the estimated incentives provided by stock. An example where bias is less important is when the researcher wishes to examine cross-sectional variation in the use of firm-wide option plans.

The prevalence of underwater options in executive option portfolios is likely to be greatest in periods following sharp stock price declines. In these settings, researchers can improve the OA proxies using a modified OA method that requires information from one or two past proxy statements in addition to the most recent proxy statement. To implement this modified method, the researcher first identifies the most recent proxy statement that pre-dates the recent stock price decline (e.g., use 1999 
proxy statements that pre-date large price declines in 2000). Option portfolio data in this proxy statement can be used to estimate the average exercise price of options held by the executive as of this date. Option grant and exercise data from the more recent proxy statement to infer an estimate of the average exercise price of the option portfolio at the researchers desired date (e.g., estimate the average exercise price at 1999 and subtract option exercises during 2000 to obtain the average exercise price of previously granted options at 2000). A second potential approach is to use the observed price-tostrike ratio as a proxy for the measurement error in the OA estimate. ${ }^{9}$

A source of second-order measurement error in the OA method stems from the nonlinear relation between the price-to-strike ratio and option value and sensitivities (see Figure 1). The OA method uses the two exercise price estimates derived from previously granted exercisable and unexercisable options to "interpolate" this nonlinear relation. The magnitude of the "interpolation" error is an increasing function of the standard deviation of the true price-to-strike ratios across the options in the portfolio. ${ }^{10}$ The measurement error problem is more severe in the regions where the underlying function is most non-linear. Figure 1 illustrates that the departures from linearity are greatest for sensitivity to price when options are out-of-the-money. Option value also exhibits the greatest departure from linearity when options are out-of-the-money. Consistent with this observation, we find that this source of measurement error is greatest for OA measures of portfolio value and the sensitivity to price when the

\footnotetext{
${ }^{9}$ For example, if a regression used the OA estimate of option incentives as an explanatory variable, including the observed price-to-strike ratio in the regression would lessen the bias in the estimated coefficient on the incentive variable due to measurement error, provided that the price-to-strike ratio is uncorrelated with the dependent variable (e.g., Brown, Hagerman, Griffin, and Zmijewski, p. 186).

${ }^{10}$ Although the standard deviation of price-to-strike ratios in a portfolio is not observed, the researcher could proxy for it using the standard deviation of recent stock returns (e.g., over a five-year period) or could estimate it by gathering data on variation in exercise prices of past grants.
} 
observed price-strike-ratio is less than 1.1 (untabulated). ${ }^{11}$ This measurement error exacerbates the first-order biases described above for low price-to-strike ratio portfolios. There is little increase in measurement error in subsamples where the observed price-to-strike ratio is greater than 1.1. With respect to the sensitivity to volatility, Figure 1 indicates that non-linearity is generally greater for in-themoney options. However, the magnitude of the bias due to this non-linearity is minor in all subsamples we examine.

Another source of second-order measurement error derives from the fact that the proxy statement does not provide complete information about the remaining times-to-maturity of previously granted options. While the assumptions that previously granted unexercisable (exercisable) options have times-to-maturity of one (four) years less than the time-to-maturity of newly granted options seem reasonable on average, these assumptions result in some degree of measurement error for any given firm. For example, in firms with strong performance, a greater proportion of older, in-the-money options are likely to have been exercised because employees forfeit less time value of the options by exercising early.

When options are substantially out-of-the-money, over-estimating the time-to-maturity imparts an upward bias on measures of sensitivity to stock price. This is because a short-maturity, out-of-themoney option has little chance of generating a positive payoff, and so has an actual sensitivity to stock price that is close to zero. The reverse argument is true for options that are substantially in-the-money. In the computation of sensitivity to volatility, the time-to-maturity is a multiplicative term (see Appendix

\footnotetext{
${ }^{11}$ To examine this source of measurement error, we compute the standard deviation of the actual price-to-strike ratios for the previously granted options in each simulated portfolio and examine measurement error in the OA proxies for firms in the top quartile of price-to-strike standard deviation.
} 
A), and so an over-estimate of the time-to-maturity results in upwardly biased estimates for all price-tostrike ratios.

\subsection{SYSTEMATIC MEASUREMENT ERROR AND COMPARISON OF ALTERNATIVE PROXIES}

In Tables 1 and 2, we provide evidence that, on average, measurement error in the OA proxies is small. If the estimation error in a proxy is simply noise, the power of a researcher's tests is reduced and there is a risk of making a Type II error, i.e., the null hypothesis is not rejected when it is false. However, if the measurement error is correlated with other important explanatory variables, a Type I error can be made, i.e., the null hypothesis is rejected when it is true. To emphasize the usefulness of the OA proxies and to provide a basis for evaluating the results of past research, we now address the extent to which these proxies improve upon other proxies used in the literature.

Many prior studies examine the incentives that stock option portfolios provide executives to increase stock price and stock-return volatility. Although some studies use a variant of the FI sensitivity, many researchers use more easily computed proxies to capture these incentive effects that include: 1) the number of options held by the executive; 2) the number of options held by the executive multiplied by the stock price; 3) the sensitivities of only newly granted options. Although all of these alternative proxies are likely to be correlated with variation in option portfolio sensitivities, they are expected to suffer from predictable measurement error. For example, the total number of options captures the extent of option use, but fails to incorporate cross-sectional variation in the characteristics of the options, such as time-to-maturity, volatility, and exercise price. The sensitivities of newly granted options ignores incentives provided by previously granted options, and the correlation between the sensitivities of newly granted options and previously granted options is quite small (e.g., for the sensitivity to stock price, the correlation is 0.2 in our sample). 
To assess the degree of systematic variation in measurement error, we regress the fullinformation value and sensitivities to stock price and stock-return volatility on the proxies for these measures, and the Black-Scholes parameters underlying the CEOs' option portfolios.$^{12}$ If a proxy fully reflects the information in the underlying Black-Scholes parameters, then the addition of these parameters to the regression should not add explanatory power. To ease the comparison of coefficients across regressions, all variables are standardized to have a mean of zero and a standard deviation of one.

The results in Table 3 indicate that the OA proxy for the sensitivity to stock price has little systematic error, and substantially less systematic error than the alternative proxies. Column (1) reports results for the OA proxy. With the exception of the mean price-to-strike ratio, none of the regression coefficients on the Black-Scholes parameters are distinguishable from zero. The positive and significant coefficient on the mean price-to-strike ratio is not surprising given the results in Table 2 that show the $\mathrm{OA}$ estimate is larger than the FI estimate when the price-to-strike ratio is low, and that this bias becomes smaller as the price-to-strike ratio increases. Although not tabulated, the regression results for option portfolio value and the sensitivity to stock-return volatility are similar to those reported in Table 3.

The results in Columns (2) through (4) of Table 3 suggest that the degree of systematic error in the alternative proxies is substantially greater than that in the OA proxy. Measurement error in each of the alternative proxies is significantly related to no fewer than two, and as many as four, of the option portfolio characteristics. By comparison, the systematic error in the OA proxy is related to only one

\footnotetext{
${ }^{12}$ We do not include the risk-free rate in the regression analysis because, except for non-linearities in the yield curve, it is perfectly correlated with mean time-to-maturity in cross-section and, as such, creates a severe multi-collinearity
} 
characteristic. Further, and even more importantly, the magnitude of the systematic error tends to be several times larger for the alternative proxies compared to the OA proxy. Since all variables are standardized, the coefficients can be interpreted as partial correlations and compared across regressions. For example, the partial correlation on the mean price-to-strike ratio for the OA proxy is 0.01 compared to correlations ranging from 0.07 to 0.20 for the other proxies. ${ }^{13}$

\section{Summary and Conclusion}

We present and validate a one-year approximation method (the OA method) for estimating the value of an executive's stock option portfolio and the sensitivities of option portfolio value to stock price and stock-return volatility. The OA method uses readily accessible data from the current year's proxy statement and can be easily modified to estimate firm-wide option plan value and sensitivities using data from the current year's annual report. In a broad sample of hand-collected and simulated CEO option portfolios, we show that the OA proxies are unbiased and capture more than $99 \%$ of the crosssectional variation in option portfolio value and sensitivities. Based on the assumptions that underlie the OA method, we describe potential sources of measurement error, and document the magnitude of this error in subsamples of our data. We also highlight research settings where this measurement error is likely to be especially problematic (e.g., portfolios with a large proportion of options with low price-tostrike ratios), and suggest approaches for either reducing the error and/or mitigating the effect of the

problem.

${ }^{13}$ Our tests focus on the level of option portfolio sensitivities (as defined in Section 2). However, some other researchers use deflated proxies for CEO incentives. For example, both Jensen and Murphy [1990] and Yermack [1995] measure equity incentives as the change in CEO wealth per $\$ 1,000$ change in shareholder value. This measure is equal to the sensitivity to stock price, as defined in Section 2, deflated by the market value of equity and multiplied by $\$ 100,000$. We re-estimate the results in Table 3 after deflating the full-information sensitivity and the alternative proxies by the market value of equity. The deflated results (not reported but available upon request) are qualitatively similar to those reported in Table 3 , with the only exception being that the OA proxy provides a smaller improvement over the alternative proxy reported in Column 2 (the number of options times stock price). 
error on regression estimates. Finally, we present evidence that the OA proxies exhibit greater power and less bias than alternative proxies used in the literature.

The OA proxies presented and validated in this paper should improve the power, reduce potential bias, and lower the costs of empirical tests that require estimates of stock option portfolio value and sensitivities. For example, because the OA proxies estimate the actual value and sensitivities of option portfolios, they have a direct economic interpretation and can be combined with the sensitivities from stockholdings and/or bonuses to generate aggregate sensitivities for managers. Further, alternative proxies for option portfolio sensitivities to stock price and volatility, such as the number of options held, do not provide an empirically distinct measure of either sensitivity. This drawback is problematic in many research areas, such as risk management, where the researcher's tests often require simultaneous separate estimates of sensitivities to stock price and volatility (e.g., Tufano [1996]). By contrast, because the OA proxies provide direct estimates for each of the two sensitivities (depicted in Figure 1), they are empirically distinct. 


\section{APPENDIX A}

\section{Calculating Black-Scholes Value and Sensitivities of Individual Stock Options}

Estimates of a stock option's value or sensitivity to stock price or stock-return volatility are calculated based on the Black-Scholes [1973] formula for valuing European call options, as modified to account for dividend payouts by Merton [1973].

$$
\text { Option value }=\left[S \mathrm{e}^{-\mathrm{dT}} \mathrm{N}(Z)-\mathrm{X} \mathrm{e}^{-\mathrm{rT}} \mathrm{N}\left(Z-\sigma \mathrm{T}^{(1 / 2)}\right)\right],
$$

where

$Z=\left[\ln (S / X)+T\left(r-d+\sigma^{2} / 2\right)\right] / \sigma T^{(1 / 2)}$,

$\mathrm{N}=\quad$ cumulative probability function for the normal distribution

$\mathrm{S}=\quad$ price of the underlying stock

$\mathrm{X}=$ exercise price of the option

$\sigma=\quad$ expected stock-return volatility over the life of the option

$r=$ natural logarithm of risk-free interest rate

$\mathrm{T}=\quad$ time to maturity of the option in years

$\mathrm{d}=\quad$ natural logarithm of expected dividend yield over the life of the option

The sens itivity with respect to a $1 \%$ change in stock price is defined as:

$[\partial($ option value $) / \partial($ price $)] *($ price $/ 100)=\mathrm{e}^{-\mathrm{dT}} \mathrm{N}(Z) *($ price $/ 100)$

The sensitivity with respect to a 0.01 change in stock-return volatility is defined as:

$[\partial($ option value $) / \partial($ stock volatility $)] * 0.01=\mathrm{e}^{-\mathrm{dT}} \mathrm{N}^{\prime}(Z) \mathrm{S} \mathrm{T}^{(1 / 2) *}(0.01)$, where $\mathrm{N}^{\prime}=$ normal density function 


\section{REFERENCES}

ABOODY, D. "Market Valuation of Employee Stock Options." Journal of Accounting and Economics 22 (1996): 357-391.

ABOwD, J.M., AND D.S. KAPLAN. 'Executive Compensation: Six Questions that Need Answering." Journal of Economic Perspectives 13, (Fall 1999): 145-168.

BLACK, F., AND M. SCHOLES. "The Pricing of Options and Corporate Liabilities." Journal of Political Economy 81 (1973): 637-654.

Brown, L., R. Hagerman, P. Griffin, and M. Zmijewski. "An Evaluation of Alternative Proxies for the Market's Assessment of Unexpected Earnings" Journal of Accounting \& Economics 9 (1987): 159193.

CORE, J., AND W. GUAY, "Stock Option Plans for Non-executive Employees." Journal of Financial Economics 61 (2001a): 253-287.

CORE, J., AND W. GUAY, "When Contracts Require Risk-Averse Executives to Hold Equity: Implications for Option Valuation and Relative Performance Evaluation." Working paper, University of Pennsylvania (2001b).

CUNY, C., AND P. JORION. "Valuing Executive Stock Options with a Departure Decision." Journal of Accounting and Economics 20 (1995): 193-205.

GUAY, W. "An Empirical Analysis of Convexity in the Relation Between CEOs' Wealth and Stock Price." Journal of Financial Economics 53 (1999): 43-71.

HALL, B. J., AND J. B. LIEBMAN. "Are CEOs Really Paid Like Bureaucrats?" Quarterly Journal of Economics 113 (1998): 653-691.

HeMmer, T.; S. MATSUNAGA; AND T. SHEVLIN. "The Influence of Risk Diversification on the Early Exercise of Stock Options by Executive Officers. ” Journal of Accounting and Economics 21 (1996): 45-68.

HUDDART, S. "Employee Stock Options." Journal of Accounting and Economics 18 (1994): 207-231.

HUDDART, S., AND M. LANG. "Employee Stock Option Exercises: An Empirical Analysis." Journal of Accounting and Economics 21 (1996): 5-43.

JENSEN, M., AND K. MURPHY. "Performance Pay and Top-management Incentives." Journal of Political Economy 98 (1990): 225-264. 
KOLE, S. R. "The Complexity of Compensation Contracts." Journal of Financial Economics 43 (1997): 79-104.

LAMBERT, R.; W. LANEN; AND D. LARCKER. 'Executive Stock Option Plans and Corporate Dividend Policy." Journal of Financial and Quantitative Analysis 24 (1989): 409-425.

LAMBERT, R.; D. LARCKER; AND R. VERRECCHIA. "Portfolio Considerations in Valuing Executive Compensation." Journal of Accounting Research 29 (1991): 129-149.

Mehran H.; G. Nogler; AND K. Schwartz. "CEO Incentive Plans and Corporate Liquidation Policy." Journal of Financial Economics 50 (1998): 319-349.

MERTON, R. "Theory of Rational Option Pricing." Bell Journal of Economics and Management Science 4 (1973): 141-183.

MurPHY, K. "Executive Compensation." in Ed. O Ashenfelter and D. Card." Handbook of Labor Economics, Vol. 3, Amsterdam: North-Holland, 1999.

Tufano, P. "Who Manages Risk? An Empirical Examination of Risk Management Practices in the Gold Mining Industry." Journal of Finance 51 (1996): 1097-1137.

YERMACK, D. 'Do Corporations Award CEO Stock Options Effectively?' Journal of Financial Economics 39 (1995): 237-269. 
Figure 1. The sensitivity of option value to stock price and stock-return volatility as a function of the price-to-strike ratio

The sensitivities are based on an underlying option with a maturity of 7 years on a stock with a price of $\$ 100$. The exercise price of the option is determined by the price-to-strike ratio. The stock's dividend yield is $3 \%$, the annualized standard deviation of stock returns is 0.30 , and the risk-free rate is $7 \%$. The sensitivity to stock price is the change in option value for a $1 \%$ change $(\$ 1)$ in stock price, and the sensitivity to volatility is the change in option value for a 0.01 change in stock-return volatility.

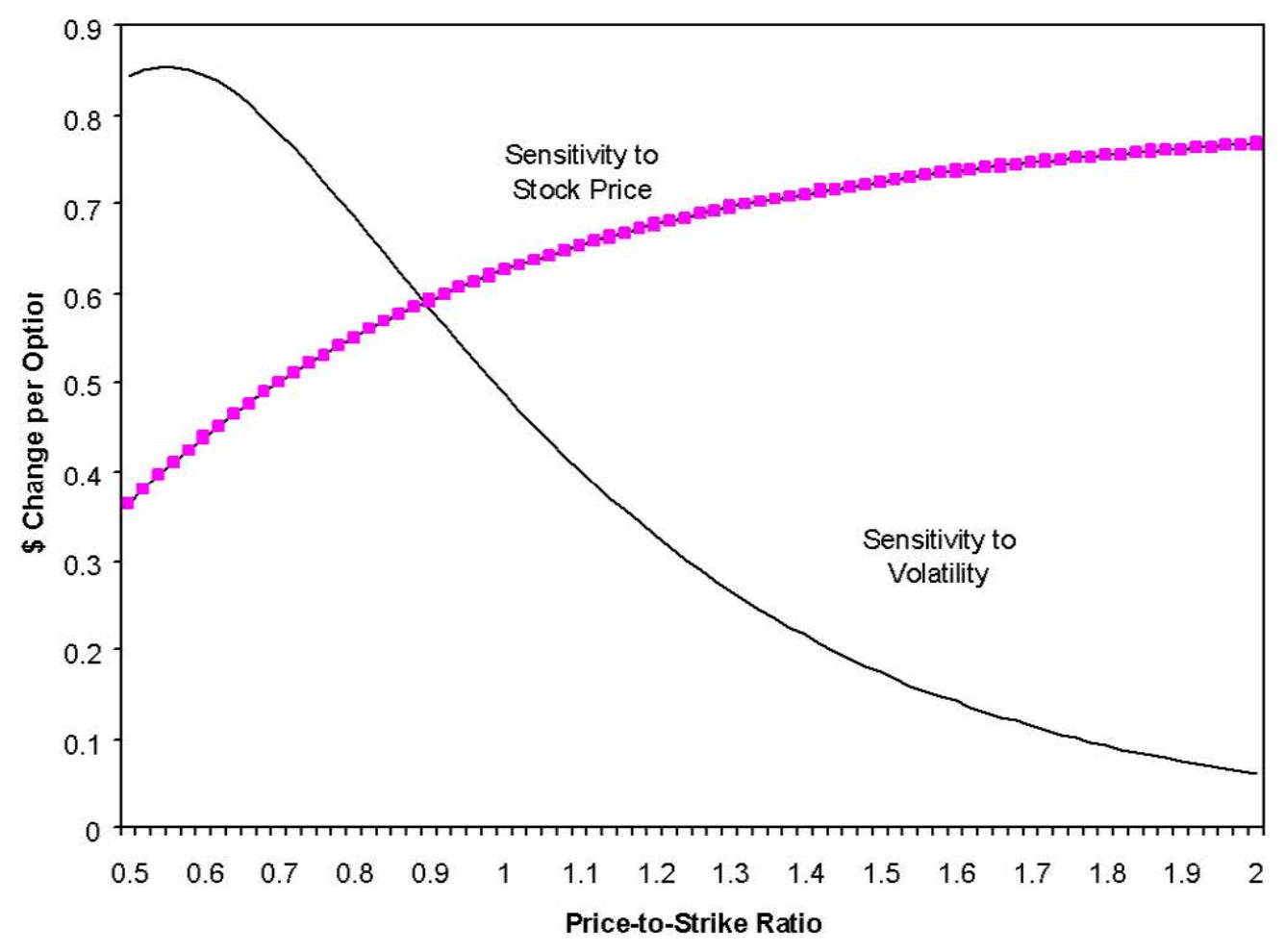


TABLE 1

Performance of One-Year Approximation Proxies: Comparison with Full-Information measures

\begin{tabular}{|c|c|c|c|c|c|c|}
\hline \multirow[b]{2}{*}{ One-year approximation proxy } & \multicolumn{3}{|c|}{228 hand-collected CEO option portfolios } & \multicolumn{3}{|c|}{10,000 simulated CEO option portfolios } \\
\hline & $\begin{array}{l}\% \text { Error in } \\
\text { sample mean } \\
\text { (1) }\end{array}$ & $\begin{array}{c}\% \text { Error in } \\
\text { sample median } \\
\text { (2) }\end{array}$ & $\begin{array}{l}\mathrm{R}^{2} \text { with full } \\
\text { information measure } \\
\text { (3) }\end{array}$ & $\begin{array}{c}\% \text { Error in } \\
\text { sample mean } \\
\text { (4) }\end{array}$ & $\begin{array}{c}\text { \%Error in } \\
\text { sample median } \\
(5)\end{array}$ & $\begin{array}{l}\mathrm{R}^{2} \text { with full } \\
\text { information measure } \\
\text { (6) }\end{array}$ \\
\hline Value of option portfolio & $0.1 \%$ & $4.0 \%$ & $99.7 \%$ & $5.6 \% * * * *$ & $6.0 \% * * * *$ & $99.5 \%$ \\
\hline $\begin{array}{l}\text { Sensitivity of option portfolio } \\
\text { value to stock price }\end{array}$ & $1.1 \%$ & $2.9 \%$ & $99.7 \%$ & $1.7 \%$ & $1.0 \%$ & $99.6 \%$ \\
\hline $\begin{array}{l}\text { Sensitivity of option portfolio } \\
\text { value to stock-return volatility }\end{array}$ & $-0.6 \%$ & $1.1 \%$ & $99.4 \%$ & $-0.9 \%$ & $-1.3 \%$ & $98.7 \%$ \\
\hline
\end{tabular}

*** Indicates that the means (medians) of the two samples are significantly different at the 0.01 level.

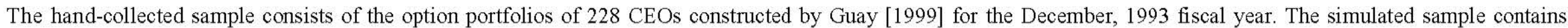

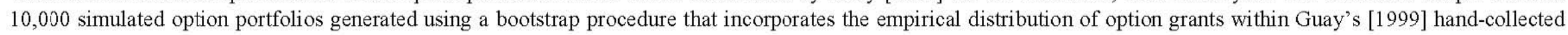
sample.

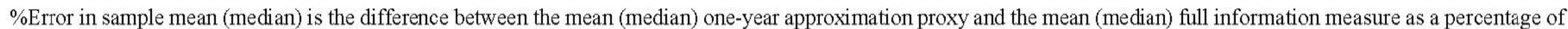

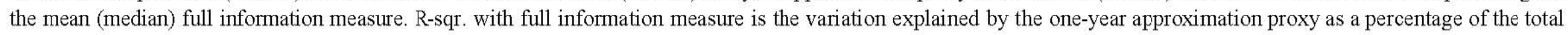
variation in the full information measure.

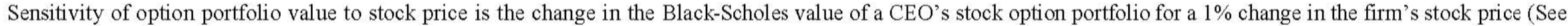

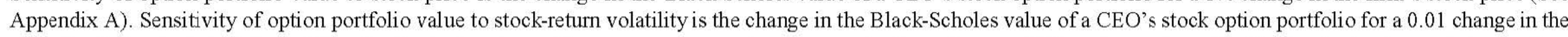
annualized standard deviation of the firm's stock returns. The one-year approximation proxies for option portfolio value and sensitivities to stock price and stock-return

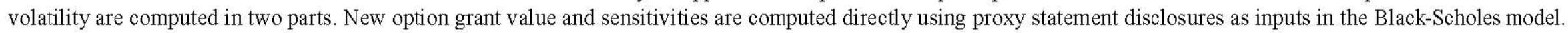
Previously granted unexercisable and exercisable options are treated as two single grants with exercise prices derived from the average realizable value of the executive's

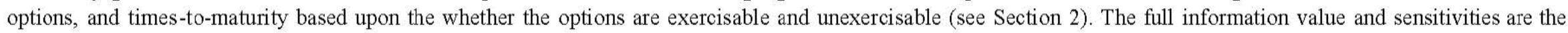
measures the researcher would compute if complete data were available about the option portfolios 
TABLE 2

Measurement Error in One-Year Approximation Proxies: Subsample Analys is (Simulated sample of portfolios partitioned by observed price-to-strike ratio of previously granted options)

\begin{tabular}{|c|c|c|c|c|c|c|c|c|}
\hline \multirow[b]{2}{*}{$\begin{array}{l}\text { Observed PTS ratio of } \\
\text { previously granted } \\
\text { options }\end{array}$} & \multirow[b]{2}{*}{$\begin{array}{c}\text { Median actual PTS } \\
\text { ratio of previously } \\
\text { granted options }\end{array}$} & \multirow[b]{2}{*}{$\begin{array}{l}\# \text { of } \\
\text { obs. }\end{array}$} & \multicolumn{2}{|c|}{ Sensitivity to stock price } & \multicolumn{2}{|c|}{$\begin{array}{c}\text { Sensitivity to stock-return } \\
\text { volatility }\end{array}$} & \multicolumn{2}{|c|}{ Option portfolio value } \\
\hline & & & $\begin{array}{l}\% \text { Error in } \\
\text { sample } \\
\text { mean }\end{array}$ & $\begin{array}{l}\mathrm{R}^{2} \text { with full } \\
\text { info. measure }\end{array}$ & $\begin{array}{l}\% \text { Error in } \\
\text { sample } \\
\text { mean }\end{array}$ & $\begin{array}{l}\mathrm{R}^{2} \text { with full } \\
\text { info. measure }\end{array}$ & $\begin{array}{l}\% \text { Error in } \\
\text { sample } \\
\text { mean }\end{array}$ & $\begin{array}{l}\mathrm{R}^{2} \text { with full } \\
\text { info. measure }\end{array}$ \\
\hline $\mathrm{PTS}=1.0$ & 0.89 & 422 & $14.7 \%$ & $96.8 \%$ & $-1.5 \%$ & $96.6 \%$ & $21.2 \%$ & $97.0 \%$ \\
\hline $1.0<\mathrm{PTS} \leq 1.1$ & 1.01 & 1,159 & $7.9 \%$ & $99.0 \%$ & $0.5 \%$ & $99.1 \%$ & $15.5 \%$ & $98.5 \%$ \\
\hline $1.1<\mathrm{PTS} \leq 1.2$ & 1.11 & 1,668 & $4.2 \%$ & $99.5 \%$ & $2.9 \%$ & $98.9 \%$ & $9.5 \%$ & $99.4 \%$ \\
\hline $1.2<\mathrm{PTS} \leq 1.5$ & 1.29 & 3,955 & $1.2 \%$ & $99.8 \%$ & $3.8 \%$ & $99.1 \%$ & $4.5 \%$ & $99.7 \%$ \\
\hline $1.5<$ PTS & 1.70 & 2,507 & $-0.7 \%$ & $99.8 \%$ & $2.7 \%$ & $98.2 \%$ & $0.6 \%$ & $99.8 \%$ \\
\hline Full sample $=1.30$ & 1.27 & 9,711 & $2.0 \%$ & $99.6 \%$ & $2.8 \%$ & $98.7 \%$ & $5.2 \%$ & $99.5 \%$ \\
\hline
\end{tabular}

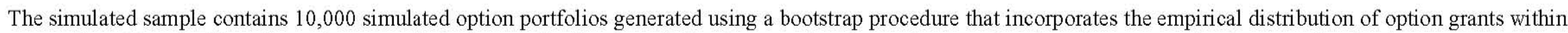
Guay's [1999] hand-collected sample. We exclude the 289 simulated portfolios that contain only newly granted options (i.e., no previously granted options).

Sensitivity of option portfolio value to stock price is the change in the Black-Scholes value of a CEO's stock option portfolio for a $1 \%$ change in the firm's stock price (See Appendix A). Sensitivity of option portfolio value to stock-return volatility is the change in the Black-Scholes value of a CEO's stock option portfolio for a 0.01 change in the annualized standard deviation of the firm's stock returns. The one-year approximation proxies for option portfolio value and sensitivities to stock price and stock-return volatility are computed in two parts. New option grant value and sensitivities are computed directly using proxy statement disclosures as inputs in the Black-Scholes model. Previously granted unexercisable and exercisable options are treated as two single grants with exercise prices derived from the average realizable value of the executive's options, and times-to-maturity based upon the whether the options are exercisable and unexercisable (see Section 2). The full information value and sensitivities are the measures the researcher would compute if complete data were available about the option portfolios.

\%Error in sample mean is the difference between the one-year approximation proxy and the full information measure as a percentage of the full information measure. R-sqr. with full information measure is the variation explained by the one-year approximation proxy as a percentage of the total variation in the full information measure. The observed PTS ratio of previously granted options is the average portfolio price-to-strike ratio for previously granted exercisable and unexercisable options that the researcher computes using the one-year approximation method. The actual PTS ratio of previously granted options is the average portfolio price-to-strike ratio of previously granted exercisable and unexercisable options. The observed PTS ratio differs from the actual PTS ratio when the portfolio contains previously granted options that are out-of-themoney. 
TABLE 3

Systematic Measurement Error in Alternative Proxies for Sensitivity to Stock Price

(Regressions of full-information sensitivity to stock price on alternative proxies and option characteristics)

Dependent variable: Full-information sensitivity to stock price

(1) (2) (3) (4)

Proxy:

Sensitivity to stock price: One-year

$0.99 * *$

approximation method

(235.84)

Total number of options held *

$0.94 * *$

Stock price

(59.75)

Total number of options held

$0.72 * *$

(22.53)

Sensitivity to stock price: New

$0.45 * *$

option grant only

(8.84)

\section{Option portfolio characteristics:}

\begin{tabular}{lcccc} 
Mean price-to-strike ratio & $0.01 * *$ & $0.07 * *$ & $0.09 * *$ & $0.20 * *$ \\
Mean time-to-maturity & $(2.55)$ & $(4.72)$ & $(2.69)$ & $(3.93)$ \\
Stock price & -0.00 & -0.02 & $-0.06^{*}$ & $-0.16^{* *}$ \\
Std. dev. of stock returns & $(-0.23)$ & $(-1.55)$ & $(-1.83)$ & $(-3.22)$ \\
& 0.00 & -0.02 & $0.46 * *$ & $0.36 * *$ \\
Dividend yield & $(0.51)$ & $(-0.84)$ & $(12.49)$ & $(5.88)$ \\
& -0.00 & -0.03 & -0.00 & 0.08 \\
\hline Adjusted R & $(-0.90)$ & $(-1.59)$ & $(-0.05)$ & $(1.17)$ \\
Incremental adjusted $\mathrm{R}^{2}$ from & -0.00 & $-0.11 * *$ & $-0.08 * *$ & $-0.13 * *$ \\
option portfolio characteristics & $(-0.65)$ & $(-6.77)$ & $(-2.11)$ & $(-2.21)$ \\
\hline P-value for incremental $\mathrm{R}^{2}$ & $99.7 \%$ & $95.9 \%$ & $78.7 \%$ & $48.3 \%$ \\
\hline \hline
\end{tabular}

The sample consists of the option portfolios of 228 CEOs hand-collected by Guay [1999] for the December, 1993 fiscal year. t-statistics in parentheses. ${ }^{*}$ denotes significance at the 0.10 level. ${ }^{* *}$ denotes significance at the 0.05 level.

All variables are standardized to have a mean of zero and a standard deviation of one. Sensitivity to stock price is the change in the Black-Scholes value of a CEO's stock option portfolio for a $1 \%$ change in the firm's stock price. Sensitivity to stock price estimated using the one-year approximation method is described in Section 2. Sensitivity to stock price: New option grant only excludes previously granted options. Mean price-to-strike ratio and mean time-to-maturity are computed using full information data. 